\title{
Interleukin-11 Potentiates Oligodendrocyte Survival and Maturation, and Myelin Formation
}

\author{
Yueting Zhang, ${ }^{1,2}$ Carla Taveggia, ${ }^{3}$ Carmen Melendez-Vasquez, ${ }^{3}$ Steven Einheber, ${ }^{4}$ Cedric S. Raine, ${ }^{5,6}$ James L. Salzer, ${ }^{3}$ \\ Celia F. Brosnan, ${ }^{5,6}$ and Gareth R. John ${ }^{1,2,5}$ \\ ${ }^{1}$ Corinne Goldsmith Dickinson Center for Multiple Sclerosis and 2Department of Neurology, Mount Sinai School of Medicine, New York, New York 10029, \\ ${ }^{3}$ Department of Cell Biology, Skirball Institute of Biomolecular Medicine, New York University School of Medicine, New York, New York 10016, ${ }^{4}$ Hunter \\ College School of Health Sciences, New York, New York 10010, and Departments of ${ }^{5}$ Pathology (Neuropathology) and ${ }^{6}$ Neuroscience, Albert Einstein \\ College of Medicine, Bronx, New York 10461
}

\begin{abstract}
Mechanisms that regulate oligodendrocyte survival and myelin formation are an intense focus of research into myelin repair in the lesions of multiple sclerosis (MS). Although demyelination and oligodendrocyte loss are pathological hallmarks of the disease, increased oligodendrocyte numbers and remyelination are frequently observed in early lesions, but these diminish as the disease course progresses. In the current study, we used a microarray-based approach to investigate genes regulating repair in MS lesions, and identified interleukin-11 (IL-11) as an astrocyte-derived factor that potentiates oligodendrocyte survival and maturation, and myelin formation. IL-11 was induced in human astrocyte cultures by the cytokines IL-1 $\beta$ and TGF $\beta 1$, which are both prominently expressed in MS plaques. In MS tissue samples, IL-11 was expressed by reactive astrocytes, with expression particularly localized at the myelinated border of both active and silent lesions. Its receptor, IL-11R $\alpha$, was expressed by oligodendrocytes. In experiments in human cultures in vitro, IL-11R $\alpha$ localized to immature oligodendrocytes, and its expression decreased during maturation. In cultures treated with IL-11, we observed a significant increase in oligodendrocyte number, and this was associated with enhanced oligodendrocyte survival and maturation. Importantly, we also found that IL-11 treatment was associated with significantly increased myelin formation in rodent CNS cocultures. These data are the first to implicate IL-11 in oligodendrocyte viability, maturation, and myelination. We suggest that this pathway may represent a potential therapeutic target for oligodendrocyte protection and remyelination in MS.
\end{abstract}

Key words: astrocyte; cytokine; myelin; multiple sclerosis; oligodendrocyte; repair

\section{Introduction}

The pathological hallmarks of multiple sclerosis (MS) are multifocal sites of CNS inflammation associated with blood-brain barrier breakdown, demyelination, oligodendrocyte depletion, progressive axonal loss, and a reactive astrogliosis (Raine, 1997; Brück and Stadelmann, 2005; Frohman et al., 2006). Areas of remyelination are frequently observed in lesions early in the course of the disease, and correlate with the return of efficient conduction (Smith et al., 1981; Brück et al., 2003). However, it is also clear that remyelination gradually fails as MS progresses, although the mechanisms underlying this loss of regenerative capacity are not well understood. Current treatments for MS aim

\footnotetext{
Received 0ct. 17, 2005; revised Sept. 11, 2006; accepted 0ct. 4, 2006.

This work was supported by United States Public Health Service Grants NS46620 (G.R.J.), NS40137 (C.F.B.), NS08952 (C.S.R.), NS11920 (C.F.B., C.S.R.), and NS26001 (J.L.S.); by National Multiple Sclerosis Society (NMSS) Grants RG2311 (J.L.S.) and RG1001 (C.S.R.); by NMSS Postdoctoral Fellowships FG1739 (Y.Z.) and FG1541 (C.T.); and by the Jayne and Harvey Beker Foundation (G.R.J.). The Mount Sinai School of Medicine (MSSM) Microscopy Shared Resource Facility is supported, in part, with funding from National Institutes of Health-National Cancer Institute Shared Resources Grant R24 CA095823. We thank Dr. Bradford Poulos (Director of the Human Fetal Tissue Repository, Albert Einstein College of Medicine) for tissue collection, Dr. Teresa Milner (Weill Medical College of Cornell University, New York, NY) for help with electron microscopy, and Dr. Robert Hennigan (MSSM Microscopy Shared Resource Facility).

Correspondence should be addressed to Dr. Gareth R. John, Department of Neurology, Annenberg 14-86, Box 11-37, Mount Sinai School of Medicine, New York, NY 10029. E-mail: gareth.john@mssm.edu.

D0I:10.1523/JNEUROSCI.2289-06.2006

Copyright $\odot 2006$ Society for Neuroscience $\quad$ 0270-6474/06/2612174-12\$15.00/0
}

to reduce the incidence and severity of new lesion formation and clinical relapses, but these approaches have, to date, demonstrated little beneficial effect on regeneration and remyelination (Kieseier et al., 2005). For this reason, myelin repair and neuroprotection remain major goals for MS therapy.

Accumulating evidence suggests that mediators produced locally play an important role in determining the success or failure of repair in the lesions of MS, and the keys to understanding remyelination may therefore lie in molecular study of the lesion environment (Franklin, 2002). Reactive astrocytes represent the most abundant cellular component of the MS plaque (Holley et al., 2003), and these cells have been implicated as regulators of CNS inflammation and repair (Bush et al., 1999; Faulkner et al., 2004). They have also been shown to express factors that regulate oligodendrocyte survival and/or maturation in vitro (Komoly et al., 1992; Wolswijk and Noble, 1992; Mayer et al., 1994; Gard et al., 1995; Redwine and Armstrong, 1998; Wu et al., 2000; John et al., 2002; Back et al., 2005). As such, reactive astrocytes represent a logical target for analysis in attempts to understand the mechanisms controlling remyelination. Cytokines involved in the induction of CNS inflammation and a reactive astrogliosis include interleukin-1 $\beta$ (IL$1 \beta)$, transforming growth factor $\beta 1$ (TGF $\beta 1$ ), and interferon- $\gamma$ (IFN $\gamma$ ), each of which is believed to induce a specific transcriptional response and functional phenotype (for review, see John et al., 2003).

In the current study, we investigated potential links between 
astrocyte reactivity and lesion repair using microarray analysis of cytokine-activated primary human fetal astrocytes. This approach identified IL-11, a gp130 family member, as a factor specifically induced in response to IL- $1 \beta$ or TGF $\beta 1$. Cytokines of the gp130 family, including leukemia inhibitory factor (LIF) and ciliary neurotrophic factor (CNTF), have been shown to play a dual role in the response to CNS injury, acting as regulators of both inflammation and progenitor differentiation (Butzkueven et al., 2002; Linker et al., 2002), and are therefore of potential interest in the context of MS. Although minimal information is available concerning the role of IL-11 in the postnatal CNS, the chromosomal region containing the IL-11 gene $(19 q 13)$ has been linked to MS by genetic studies (Barcellos et al., 1997; Green et al., 2001). We therefore hypothesized that IL-11 might play a role in regulating oligodendrocyte survival and maturation, and myelin formation in the MS lesion, and the results of our experiments support this hypothesis. These data are the first to implicate IL-11 as a factor potentially relevant to oligodendrocyte protection and/or repair in this disease.

\section{Materials and Methods}

Cytokines/growth factors. Recombinant human IL-1 $\beta$, IL-11, TGF $\beta 1$, and LIF were purchased from Peprotech (Rocky Hills, NJ), whereas human IFN $\gamma$ and mouse IL-11 were obtained from R \& D Systems (Minneapolis, MN). IL- $1 \beta$, TGF $\beta 1$, IFN $\gamma$, and LIF were used at $10 \mathrm{ng} / \mathrm{ml}$, based on dose-response studies that we and others have performed previously on cytokine-mediated signal transduction events in human astrocytes (Liu et al., 1996; John et al., 2002), and other cell types (Delhase et al., 1999; Adachi et al., 2005). IL-11 was used at doses ranging from 1 to $100 \mathrm{ng} / \mathrm{ml}$ based on published studies in primary cells (Enomoto et al., 2004).

Antibodies. Rabbit anti-IL-11, anti-IL-11R $\alpha$, and anti-p21 antibodies were purchased from Santa Cruz Biotechnology (Santa Cruz, CA). The A2B5 mouse hybridoma was obtained from the American Type Culture Collection (Manassas, VA), and its antibody (IgM) was prepared using standard methods. Other antibodies comprised the following: $\mathrm{O} 4$ mouse monoclonal IgM (Dr. Peter Davies, Albert Einstein College of Medicine, Bronx, NY), monoclonal mouse anti- $2^{\prime}, 3^{\prime}$-cyclic nucleotide- $3^{\prime}$ phosphodiesterase (CNPase) (IgG1) and chicken anti-neurofilament (NF-M) (Covance, Berkeley, CA), rabbit anti-GFAP (Invitrogen, Carlsbad, CA), mouse anti-GFAP (IgG1) and rabbit anti-MBP (DakoCytomation, Carpinteria, CA), mouse anti-MBP (IgG1) (Covance), mouse antiPDGFR $\alpha$ (IgG1) (R \& D Systems), and mouse anti-human Ki-67 (IgG1) (BD Pharmingen, San Diego, CA).

Tissue culture (human). Postmortem human fetal CNS tissue (19-22 weeks of gestation) was obtained from the Human Tissue Repository at the Albert Einstein College of Medicine, and all procedures were approved by the Institutional Clinical Review Committee. Cultures of primary human astrocytes were established from human fetal brain and maintained as described previously (Liu et al., 1996), whereas cultures of primary human oligodendrocytes were prepared from human fetal spinal cord as reported previously (Wilson et al., 2003), with minor modifications. Briefly, tissues were dissected and digested with papain/collagenase/trypsin/DNase (all Sigma, St. Louis, MO), to obtain cell suspensions. Cells were washed once in DMEM/F12 medium (Invitrogen), and then resuspended in DMEM/F12 supplemented with N2 medium, 1\% penicillin-streptomycin-fungizone (both Invitrogen), 336 $\mathrm{ng} / \mathrm{ml}$ thyroxine, $396 \mathrm{ng} / \mathrm{ml}$ triiodothyronine, and 1\% BSA (all Sigma), and incubated in uncoated T-25 flasks overnight at $37^{\circ} \mathrm{C}$. Nonadherent cells were then collected and plated onto poly-D-lysine-coated glass confocal plates (Mat-Tek, Ashland, MA). After $2 \mathrm{~h}$, fresh Basic Medium, with or without 1-100 ng/ml recombinant human IL-11 (Peprotech, Rocky Hill, NJ), was added to cultures, and cells were grown for $5 \mathrm{~d}$.

Tissue culture (rodent). Mouse dorsal root ganglia (DRG) neurons were isolated from embryonic day 14.5 (E14.5) and established on collagen-coated glass coverslips as described previously (Taveggia et al., 2005). Explants were cycled with FUDR (fluorodeoxyuridine) (Sigma) to eliminate all non-neuronal cells. Neuronal medium was supplemented with $50 \mathrm{ng} / \mathrm{ml}$ NGF (Harlan Bioproducts, Indianapolis, IN). Primary oligodendrocyte precursors (OPCs) were prepared as described previously from mixed glial cultures prepared from cerebral cortices of postnatal day 1 (P1) Sprague Dawley rats (Caporaso and Chao, 2001). OPCDRG neuronal cocultures were established as described previously (Chan et al., 2004). Briefly, 100,000 A2B5+ OPCs were added to cultures of purified neurons and kept in MEM containing 10\% FBS. Myelination was induced the following day by addition of $1 \mu \mathrm{g} / \mathrm{ml}$ TrkA-Fc (Chemicon, Temecula, CA). In cultures treated with IL-11, $10 \mathrm{ng} / \mathrm{ml}$ recombinant mouse IL-11 was added to A2B5+ OPCs soon after purification before seeding on purified DRGs, and the cytokine was then added fresh every other day throughout the experiment. Myelin segments were identified by MBP staining and quantitated in at least four fields in regions of the coverslip with comparable numbers of axons in four separate experiments. Preliminary immunostaining studies indicated that IL-11R $\alpha$ was expressed by rodent oligodendrocytes in a manner similar to that seen in human cultures (localizing to $\sim 53 \%$ oligodendrocytes) (see Fig. 4 ). In contrast, IL-11R $\alpha$ was expressed by only a small percentage of neurons (4.4\%), and we did not observe any relationship between axonal receptor expression and myelination status in cocultures (data not shown).

Microarray analysis. Human cDNA arrays were obtained from the Albert Einstein College of Medicine cDNA Microarray Facility (http:// microarray $1 \mathrm{k} . a e c o m . y u . e d u /)$, and each slide contained an unbiased, random collection of $27 \mathrm{~K}$ cDNA probe elements (Incyte Genomics, Palo Alto, CA). Human fetal astrocytes from four separate subjects were studied in independent experiments. Total RNA (control or cytokine treated) was extracted using the RNeasy Mini kit (Qiagen, Valencia, CA), and analyzed using an Agilent 2100 bioanalyzer. Samples without evidence of degradation were amplified once using the MessageAmp antisense RNA (aRNA) kit (Ambion, Austin, TX). After reverse transcription of aRNA, cytokine-treated samples were labeled with Cy5-fluorescent nucleotides (Amersham Biosciences, Piscataway, NJ), whereas control samples were labeled with Cy3-fluorescent nucleotides. Cy5- and Cy3-labeled cDNA samples were cohybridized to microarray slides, which were then washed, and scanned using a GenePix 4000b scanner (Molecular Devices, Union City, CA). Data were filtered, and the signal ratio of $\mathrm{Cy} 5$ to $\mathrm{Cy} 3$ was calculated for each spot to derive a relative expression value. This was then used to compare gene expression in the different experimental groups.

Real-time PCR (quantitative PCR). Cultures of primary human fetal astrocytes or oligodendrocytes were treated as described and RNA harvested using an Absolutely-RNA RT-PCR Miniprep kit (Stratagene, La Jolla, CA). cDNA was generated, and real-time PCR performed, using a previously published protocol (Yuen et al., 2002a). Each transcript in each sample was assayed in triplicate, and the mean detection threshold $\left(C_{T}\right)$ values were used to calculate $F_{p}$ values (fold-change ratios between experimental and control samples) for each gene. Amplicon size and reaction specificity were confirmed by agarose gel electrophoresis. Data validity by modeling of reaction efficiency and analysis of measurement precision have been described previously (Yuen et al., 2002b). Primers used were as follows: IL-11: sense, GAC ATG AAA CAG CAG GCT AC; antisense, CAC CCA CAA TCC CAC CTC; product, 158 bp; LIF: sense, GTT CCT GCC TTA GAG TCA TC; antisense, CAG TAT GAA ACA TCC CCA CAG; product, 194 bp; IL-6: sense, GGT CAG AAA CCT GTC CAC TG; antisense, CAA GAA ATG ATC TGG CTC TG; product, 256 bp; CNPase: sense, GTA GAG CAG GGC AAG TAA CA; antisense, GTT GGA AGG AGA AGG GAA CA; product, 221 bp; MBP: sense, TCC TGT CCT TCT CTC ACC TCC T; antisense, GTT TGC CTC CTT TTC CTC CCT C; product size, 233 bp; p21: sense, AGC GAC CTT CCT CAT CCA CC; antisense, AGA CAA CTA CTC CCA GCC C; product size, 150 bp.

Western blotting. SDS-PAGE and Western blotting were performed as previously published (Liu et al., 2000).

ELISA. Supernatants collected from confluent astrocyte cultures treated as above were analyzed for human IL-6, IL-11, and LIF protein concentrations. IL-11 and LIF were assayed using Quantikine immunoassay kits (R \& D Systems), whereas IL-6 was detected using an Elisa Max Set Deluxe kit (Biolegend, San Diego, CA).

Immunofluorescence. At times specified, cells were fixed for $10 \mathrm{~min}$ with $4 \%$ paraformaldehyde and processed for single or double immuno- 
staining, using the following combinations: Ki-67, A2B5, A2B5 plus IL$11 \mathrm{R} \alpha$, CNPase, CNPase plus IL-11R $\alpha, \mathrm{O} 4$, O4 plus GFAP, O4 plus IL$11 \mathrm{R} \alpha, \mathrm{MBP}$ plus NF. For surface antigen staining, cells were blocked with $10 \%$ goat serum in PBS for 30 min and incubated with primary antibody (A2B5, 1:15; O4, 1:25, IL-11R $\alpha, 1: 20$ ) in PBS/1\% goat serum overnight at $4^{\circ} \mathrm{C}$. After rinsing in PBS, cells were incubated in appropriate secondary antibody (1:100; all from Invitrogen) at room temperature (RT) for $1 \mathrm{~h}$. Cells were washed three times with PBS/0.3\% Triton (TPBS) to permeabilize cell membranes and were then stained for a second (intracellular) antigen, or counterstained with 4',6'-diamidino-2-phenylindole (DAPI). For intracellular antigens, cells were blocked with PBS/10\% goat serum/0.3\% Triton X-100 at RT for $30 \mathrm{~min}$, and incubated in primary antibody (CNPase, 1:100; GFAP, 1:100; Ki-67, 1:50; MBP, mouse antibody, 1:200; NF, 1:2000) in TPBS/1\% goat serum overnight at $4^{\circ} \mathrm{C}$. Cells were washed with TPBS and incubated in secondary antibody (as above) at RT for $1 \mathrm{~h}$, counterstained with DAPI to visualize cell nuclei, and mounted. Cultures were examined and photographed using an Axiovert 200 inverted fluorescence microscope imaging system with Axiovision software (Carl Zeiss MicroImaging, Thornwood, NY), and/or with a Zeiss LSM 510 META laser-scanning confocal system attached to the same microscope. In some experiments, $Z$-series stacks were collected from the confocal microscope using $0.5 \mu \mathrm{m}$ on the $z$-axis. Image analysis (including fractal analysis) was performed using NIH ImageJ $1.30 \mathrm{v}$ software.

Terminal deoxynucleotidyl transferase-mediated biotinylated UTP nick end labeling assay. Detection and quantification of apoptosis was performed using an In Situ Cell Death Detection kit (Roche, Indianapolis, IN). Oligodendrocyte cultures were fixed as above, and were first stained for $\mathrm{O} 4$ to establish cell identity, and then a terminal deoxynucleotidyl transferase-mediated biotinylated UTP nick end labeling (TUNEL) assay was performed according to the manufacturer's instructions to quantify apoptotic cells. Counterstaining with DAPI was used as a final step to quantitate total cell numbers.

5-Bromo-2'-deoxyuridine incorporation. To assess proliferating cells in our human oligodendrocyte cultures, we used a commercially available in situ 5-bromo-2'-deoxyuridine (BrdU) incorporation assay (BD Pharmingen). Briefly, BrdU (10 $\mu \mathrm{M}$; BD Pharmingen) was added to cultures for $24 \mathrm{~h}$, and cells were fixed in fixation buffer for $15 \mathrm{~min}$, and washed twice with PBS. After incubation in diluent buffer for $30 \mathrm{~min}$ to permeabilize cell membranes, $0.3 \% \mathrm{H}_{2} \mathrm{O}_{2}$ was added for 10 min to block endogenous peroxidase activity. Cells were incubated in $2 \mathrm{~N} \mathrm{HCl}$ for $1 \mathrm{~h}$ to denature nuclear DNA, followed by three washes with $0.1 \mathrm{~m}$ sodium borate, $\mathrm{pH} 8.5$ to neutralize $\mathrm{HCl}$. After antigen retrieval, immunostaining was performed according to the manufacturer's instructions, and cultures were examined and photographed using a Zeiss Axiovert microscope.

Electron microscopy. Control and treated myelinating rodent cocultures were processed as described previously (Einheber et al., 1995) or by a "stamp" method. For the latter, cultures grown on collagen-coated glass coverslips were rinsed in PBS and fixed overnight at $4^{\circ} \mathrm{C}$ in $2 \%$ glutaraldehyde diluted in $0.1 \mathrm{~m}$ phosphate buffer, $\mathrm{pH} 7.0$ ( $0.1 \mathrm{M} \mathrm{PB})$. The fixed cultures were then washed in $0.1 \mathrm{M} \mathrm{PB}$ and incubated in $2 \%$ osmium tetroxide in $0.1 \mathrm{M} \mathrm{PB}$ for $1 \mathrm{~h}$. After washing in $0.1 \mathrm{M} \mathrm{PB}$, the cultures were dehydrated through a graded series of alcohol ranging from 30 to $100 \%$, and then incubated with EMbed (Electron Microscopy Sciences, Fort Washington, PA) for $2 \mathrm{~h}$. The EMbed was removed, and capsules filled with EMbed were then inverted on top of each coverslip and allowed to sit overnight. The coverslips with inverted capsules were incubated for $2 \mathrm{~d}$ at $60^{\circ} \mathrm{C}$ to polymerize the resin. The capsules bearing the embedded cultures were then pried from the coverslips, and ultrathin sections were prepared from regions of interest. The sections were counterstained with uranyl acetate and Reynold's lead citrate and examined on a Philips (Eindhoven, The Netherlands) CM10 electron microscope.

Immunohistochemistry. Postmortem adult CNS tissue (3-48 h) from 10 MS patients, 5 age- and sex-matched normal controls, and 4 patients with other neurological diseases (ONDs), were studied. Details of the human samples used in these experiments can be found in Table 1. Sections were dewaxed and rehydrated, and then incubated in PBS/3\% $\mathrm{H}_{2} \mathrm{O}_{2}$ for 30 min, blocked with a commercially available blocking buffer
Table 1. Summary of patient samples used for immunohistochemical studies

\begin{tabular}{llllc}
\hline Diagnosis/pathology & Age & Gender & Race & Hours postmortem \\
\hline MS, acute/chronic active & 31 & F & W & 3 \\
MS, acute & 54 & F & W & 24 \\
MS, chronic active & 32 & F & W & 8 \\
MS, chronic active & 37 & F & W & 4 \\
MS, chronic active & 65 & M & H & 19 \\
MS, chronic active & 57 & F & B & 48 \\
MS, chronic active & 60 & M & W & 24 \\
MS, chronic silent & 55 & M & W & 4 \\
MS, chronic silent & 46 & M & W & 8 \\
MS, chronic silent & 53 & F & W & 19 \\
Normal & 59 & F & B & 10 \\
Normal & 59 & M & W & 18 \\
Normal & 56 & M & W & 9 \\
Normal & 56 & F & W & 22 \\
Normal & 40 & M & H & 8.5 \\
OND, ALS & 49 & F & W & 8 \\
OND, ALZ & 56 & F & W & 22 \\
OND, HIV & 33 & M & B & 6 \\
OND, HIV & 38 & M & H & 5 \\
OND, HIV & 58 & F & B & 17 \\
\hline
\end{tabular}

ALS, Amyotrophic lateral sclerosis; ALZ, Alzheimer's disease; HIV, human immunodeficiency virus; F, female; M, male; W, white; H, Hispanic; B, black.

(NEN, Boston, MA), and incubated with antibodies specific for human IL-11 (1:10), IL-11R $\alpha$ (1:10), GFAP (mouse antibody; 1:400), PDGFR $\alpha$ (1:30), or MBP (rabbit antibody; 1:500) in blocking buffer for $2 \mathrm{~h}$ at RT, and then overnight at $4^{\circ} \mathrm{C}$. After washing, sections were incubated in biotinylated secondary antibodies made in goat (1:200; Vector, Burlingame, $\mathrm{CA}$ ) for $30 \mathrm{~min}$, and developed using standard $\mathrm{ABC}$ protocols (GFAP, PDGFR $\alpha$ ) (Vector), or TSA (tyramide signal amplification) protocols (all other antigens) (NEN) followed by diaminobenzidine (DAB) (brown) or nitroblue tetrazolium (NBT) (blue) (both Sigma). For double labeling, sections were stained for IL-11 or IL-11R $\alpha$ (DAB) followed by GFAP or PDGFR $\alpha$ (NBT). Control sections were processed using species- and isotype-matched irrelevant primary antibodies, IgG fractions, or no primary antibody. All sections except those that were doublestained were then counterstained with hematoxylin, and adjacent sections were also stained with hematoxylin and eosin or Luxol fast blue to illustrate lesion pathology. Sections were then dehydrated, mounted, and examined and photographed using a CCD camera attached to an Axiophot upright microscope (Carl Zeiss MicroImaging), and image analysis was performed as above.

Statistical analysis. Statistical analysis of quantitated results was performed with Prism software (GraphPad, San Diego, CA), using appropriate tests as described in the text. A value of $p<0.05$ was considered significant.

\section{Results}

\section{IL-1 $\beta$ and TGF $\beta 1$ induce IL-11 in primary cultures of human astrocytes}

Our initial evidence that IL-11 might be upregulated in MS lesions came from cDNA microarray experiments using samples from primary human astrocytes (Fig. 1). Cultures of human fetal astrocytes were treated with cytokines known to be significantly upregulated in the brains of MS patients, including IL- $1 \beta$, IFN $\gamma$, and TGF $\beta 1$ (Cannella and Raine, 1995; Baranzini et al., 2000), and the resulting gene expression patterns were compared with untreated matched controls using microarrays of 27,000 cDNA elements representing 18,000 unique human cDNAs. This approach was similar to that which we previously used in a smallerscale study (John et al., 2002), and the resulting data demonstrated that each cytokine elicited a distinct change in the astrocyte gene profile, which in turn suggested biological significance (Fig. 1a). IL-1 $\beta$ regulated the expression of chemokines 
a.
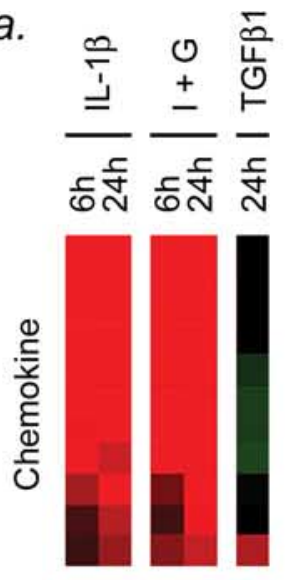

CXCL8

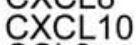

CCL 8

CXCL3

CXCL1

CXCL11

CXCL6

CX3CL1

CXCL9

CCL7

CXCR4

는

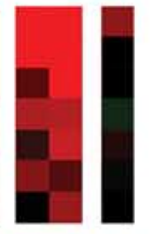

TNFL10

TNFR9

TNFR5

TNFR6

TNFL7

TNFL2

TNFR1B
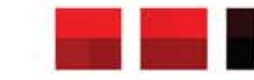

IL-15Ro

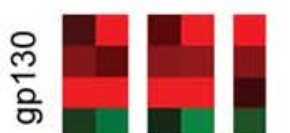

L-15

IL-11

LIF

IL-6

IL-11R

$\mathrm{IL}-13$

a.

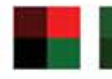

IL-13R $\alpha 1$
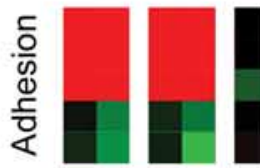

E-Selectin

ICAM-1

VCAM-1

CALL

NCAM-1

离

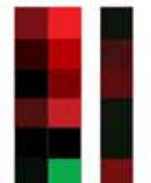

VEGF-C

HIF- $1 \alpha$

VEGF-A

Neuropilin-2

Angiopoietin-1

Gravin

$\square \square$ NOS2A

$\sum_{U}$

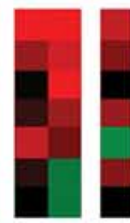

MMP7

ADAM1

MMP1

Fibronectin

Syndecan-4

ADAM12

Syndecan-2
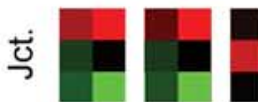

Claudin-1

Connexin26

Connexin43
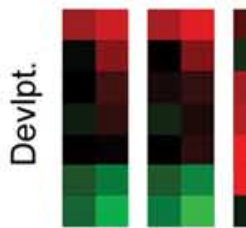

Follistatin

Semaphorin 4D

BMP4

HEY1

Lefty-A

Jagged1

Smoothened

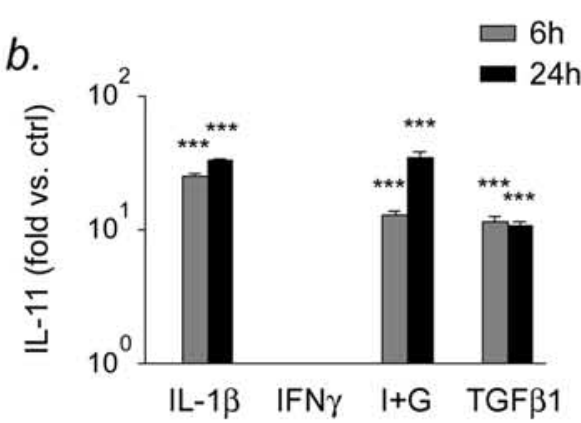

C.

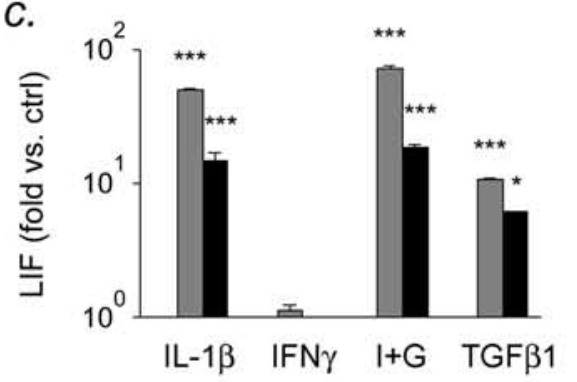

d.

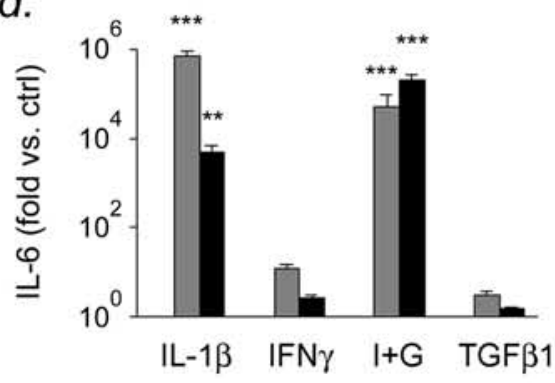

e.
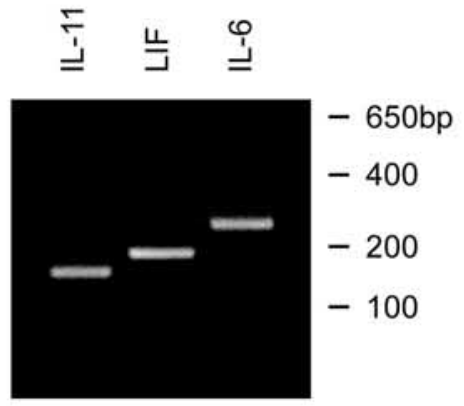

(especially CXC chemokines), cytokines [particularly members of the tumor necrosis factor (TNF) superfamily], cell adhesion molecules, and genes relevant to vascular remodeling, a pattern consistent with its proposed role in CNS inflammation and blood-brain barrier permeability (for review, see John et al., 2003). In contrast, TGF $\beta 1$ induced or modulated genes associated with extracellular matrix deposition and remodeling, a profile compatible with the role of this cytokine in the regulation of repair. TGF $\beta 1$ also induced multiple genes involved in lineage determination and/or differentiation in the developing $\mathrm{CNS}$. IFN $\gamma$ had much less dramatic effects (data not shown), although it potentiated the expression of a number of genes induced by IL-1 $\beta$ (Fig. 1a).

One of the most interesting findings of this analysis was that both IL- $1 \beta$ and TGF $\beta 1$ induced members of the gp $130 \mathrm{cy}$ tokine family, including IL-11 and LIF, whereas IL- $1 \beta$, but not TGF $\beta 1$, also induced another gp130 mediator, IL-6 (Fig. $1 a$, data marked with a red asterisk). These findings were of particular relevance to our interest in MS, because previous work has implicated members of the family, including LIF and CNTF, as regulators of both inflammation and progenitor differentiation after CNS injury (Butzkueven et al., 2002; Linker et al., 2002). Although minimal information is available concerning the potential role of IL-11 in the response to injury or inflammation, the chromosomal region containing the IL-11 gene (19q13) has been linked to MS by genetic studies (Barcellos et al., 1997; Green et al., 2001), and we therefore hypothesized that IL-11 might play a significant

Figure 1. Inflammatory cytokines elicit distinct gene expression patterns in human astrocytes: members of the gp 130 family are induced by both IL- $1 \beta$ and TGF $\beta 1$. $a$, Microarray analysis of responses of primary human fetal astrocytes exposed to IL-1 $\beta$ alone, or IL- $1 \beta$ plus IFN $\gamma(I+G)$, or TGF $\beta 1$, for 6 or $24 \mathrm{~h}$. Data have been converted to a pseudocolor map to facilitate interpretation, and abbreviations used follow standard Unigene nomenclature. Genes induced after cytokine treatment are shown in red, and genes repressed after treatment are shown in green. Note that gp130 family members, including IL-11, LIF, and IL-6, are sensitive to the effects of cytokines (asterisk). $\boldsymbol{b}$ - $\boldsymbol{e}$, Real-time $\mathrm{PCR}(\mathrm{QPCR})$ analysis of gene expression in primary human fetal astrocytes exposed to $10 \mathrm{ng} / \mathrm{ml}$ IL-1 $\beta$, IFN $\gamma$, IL-1 $\beta$ plus IFN $\gamma$, or TGF $\beta 1$ for $24 \mathrm{~h}$. Data are shown for IL-11 (b), LIF (c), and IL-6(d). Note that IL-11 and LIF are induced by either IL-1 $\beta$ or TGF $\beta 1$, whereas IL-6 is induced only by IL- $1 \beta .{ }^{* * *} p<0.001,{ }^{* *} p<$ 0.01 , and ${ }^{*} p<0.05$, ANOVA followed by Bonferroni's post test. Error bars indicate SEM. $\boldsymbol{e}$, Representative plate samples were resolved on a $2 \%$ agarose gel to confirm the specificity of the QPCRs shown in $\boldsymbol{b}$ - $\boldsymbol{d}$. Data are representative of three separate experiments on astrocytes from three different brains. ctrl, Control. 

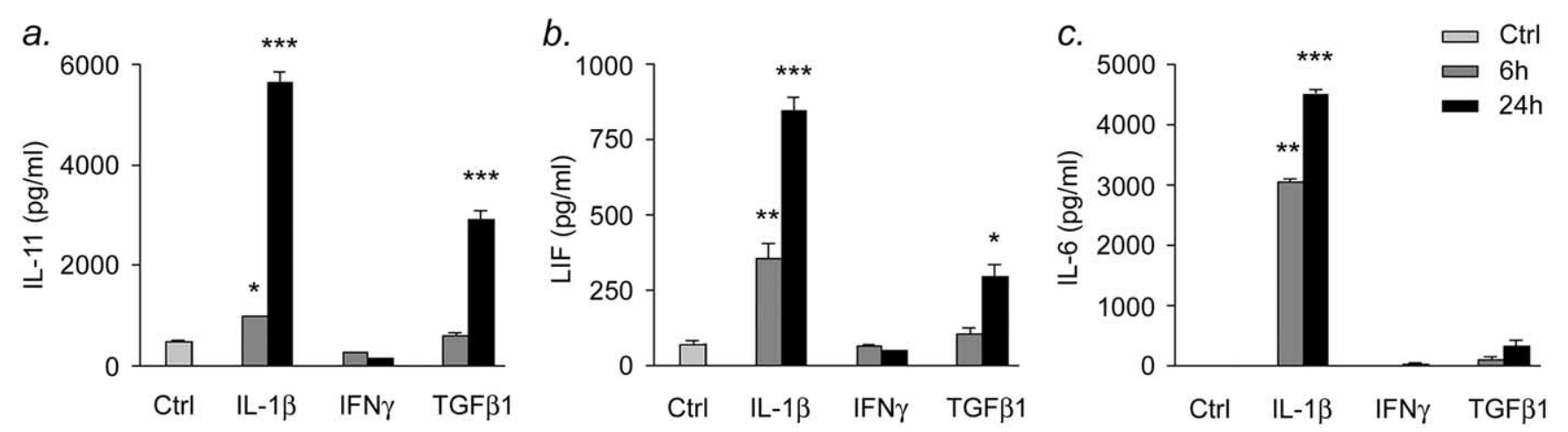

Figure 2. Protein level confirmation of gp130 family member induction in cytokine-treated human astrocytes. Sandwich ELISA analysis of gene expression in primary human fetal astrocytes exposed to $10 \mathrm{ng} / \mathrm{ml}$ IL-1 $\beta$, IFN $\gamma$, or TGF $\beta 1$ for 6 or $24 \mathrm{~h}$ is shown. Data are shown for IL-11 (a), LIF (b), and IL-6 (c). Note that IL-11 and LIF are induced by either IL- $1 \beta$ or TGF $\beta 1$, whereas IL-6 is induced only by IL-1 $\beta$. For all three gp 130 family members, maximal induction occurred at $24 \mathrm{~h}$ after treatment. ${ }^{*} p<0.05,{ }^{* *} p<0.01$, and ${ }^{* * *} p<0.001$, ANOVA followed by Bonferroni's post test. Data are representative of three separate experiments on astrocytes from three different brains. Error bars indicate SEM. Ctrl, control.

role in regulating regeneration and/or inflammation in the MS lesion. The fact that IL-11 and LIF were coregulated by both IL- $1 \beta$ and TGF $\beta 1$ was also unusual in the context of our study; very few other genes showed this expression pattern.

To verify our microarray data at the RNA and protein levels, we used quantitative PCR (QPCR) (Fig. $1 b-e$ ) and sandwich ELISA (Fig. 2). QPCR experiments confirmed potent induction of IL-11 and LIF at the mRNA level as early as $6 \mathrm{~h}$ after treatment of human fetal astrocyte cultures with IL- $1 \beta$ or TGF $\beta 1$ (Fig. $1 b, c$ ), and of IL- 6 after treatment with IL- $1 \beta$ (Fig. $1 d$ ), with levels remaining stable or decreasing thereafter. In contrast, minimal effects were observed after treatment of cultures with IFN $\gamma$, and we further observed that IFN $\gamma$ did not potentiate IL- $1 \beta$ mediated induction of gp130 family members. Compatible results were obtained using sandwich ELISA, although, as expected, upregulation of IL-11, LIF, and IL-6 at the protein level occurred after induction of mRNA, with peak concentrations occurring at $24 \mathrm{~h}$ after treatment (Fig. $2 a-c$ ).

\section{IL-11 is expressed in MS tissue samples}

To test whether these observations were relevant to events in vivo within the MS plaque, we performed immunohistochemistry for IL-11, and its receptor IL-11R $\alpha$, on autopsy adult human CNS tissue from 10 confirmed cases of MS displaying different stages of lesion activity ( 2 acute, 5 chronic active, and 3 chronic silent), 5 cases of inflammatory or noninflammatory ONDs, and 5 ageand sex-matched normal controls. Additional information concerning the samples used in these experiments can be found in Table 1, and the results of our immunohistochemistry studies are illustrated in Figure 3. Figure $3 a-d$ show a series of matching images of adjacent sections of a chronic silent MS plaque from a 32-year-old female MS patient, and they illustrate the distribution of IL-11 immunoreactivity in this sample, which was typical of our findings in other similar lesions. Staining for IL-11 was concentrated at the border of the plaque, which was mildly hypercellular and contained some myelin, although staining also extended into more extensively myelinated white matter adjacent to the lesion. Significantly less immunoreactivity was observed within the demyelinated area (Fig. $3 d$ ). These findings are quantitated in Figure $3 e$.

To determine the identity of IL-11-expressing cells, we used cell type-specific markers (Fig. $3 f-i$ ). Cells that were positive for IL-11 immunoreactivity were large and process-bearing, and appeared slightly hypertrophic (Fig. 3f). This morphology is characteristic of GFAP+ astrocytes, and double-staining for IL-11 and GFAP confirmed the identity of IL-11-expressing cells (Fig. $3 g$ ). We did not observe IL-11 immunoreactivity on other cell types, including oligodendrocytes and microglia (data not shown). In addition, we did not detect significant staining for IL-11 in CNS samples from normal controls or noninflammatory OND, although immunoreactivity was detected in some inflammatory OND (HIV) sections (data not shown).

In contrast to the pattern of expression of IL-11, we found that the localization of its ligand-specific receptor subunit, IL-11R $\alpha$, was rather different (Fig. 3h,i). Staining for IL-11R $\alpha$ was found on small cells with round nuclei in white matter areas (Fig. $3 h$ ). This morphology is typical of oligodendrocytes, and we found that IL-11R $\alpha$ staining in vivo localized to oligodendrocytes with a variety of morphologies, including interfascicular cells and individual PDGFR $\alpha+$ cells in white matter that appeared less mature. An example of a cell double-stained for IL-11R $\alpha$ and PDGFR $\alpha$ is shown in Figure 3i. We also found that, although IL-11 was expressed with a specific distribution in MS tissue samples, and was not observed in normal controls, in comparison IL-11R $\alpha$ staining was present in both MS and normal control samples, as well as in noninflammatory and inflammatory ONDs (data not shown). On the basis of these results, we hypothesized that the distribution of IL-11 rather than its receptor might be the limiting factor in IL-11 signaling in the CNS, a theory that would be compatible with previous findings for other members of the gp130 family in multiple systems (Ernst and Jenkins, 2004).

We performed staining on MS tissue samples containing several different lesion types as part of our immunohistochemical study (Table 1), and although the results shown in Figure 3 were taken from a chronic silent MS plaque, we also observed comparable findings in active lesions (see supplemental data, available at www.jneurosci.org as supplemental material). As in the case of silent MS lesions, we found that IL-11 immunoreactivity was most prominent at the partially or fully myelinated border of active plaques, and observed minimal immunoreactivity for IL-11 in demyelinated areas.

\section{IL-11 potentiates the survival and maturation of primary human oligodendroglia}

To investigate the functional effects of IL-11, we established primary cultures of human fetal spinal cord enriched for oligodendroglia using published methods (Wilson et al., 2003). These were allowed to grow and mature for $5 \mathrm{~d}$ before being fixed and stained for relevant markers. In control cultures, cells of the oli- 

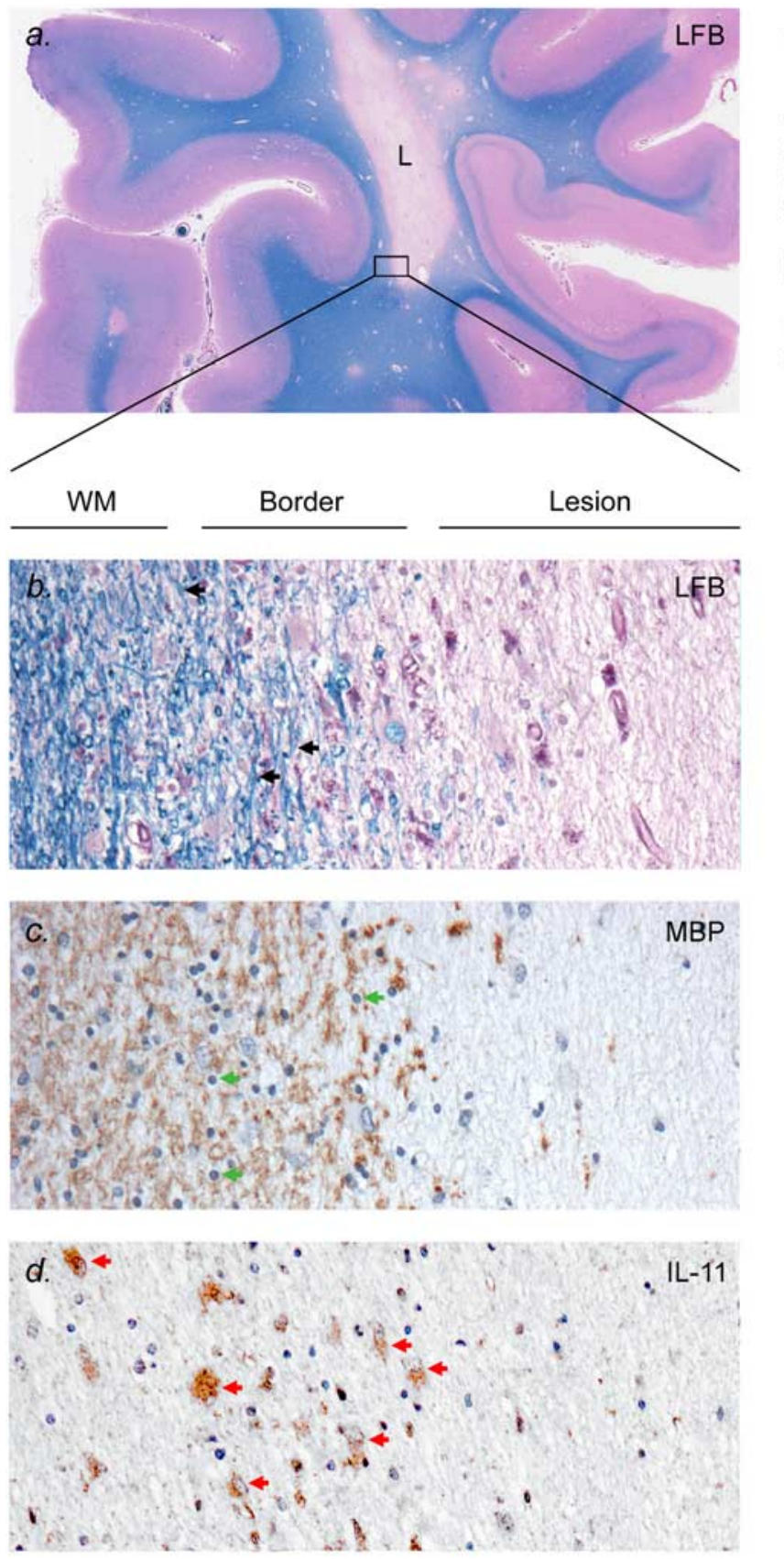

godendroglial lineage represented $\sim 77 \%$ of the total cell number after $5 \mathrm{~d}$ in vitro, and these could be further subdivided into different maturational stages on the basis of marker expression and morphology (Fig. 4). Based on these criteria, we found that the oligodendroglial component comprised $\sim 38 \%$ immature bipolar A2B5+ cells, 24\% more mature multipolar $\mathrm{O} 4+$ cells, and 15\% CNPase+ arborized oligodendrocytes (Fig. 4a,b). Some overlap of these populations was also observed, with a few A2B5 + cells also weakly positive for O4 (data not shown). The remaining $20 \%$ of cells present in these cultures were made up almost exclusively of GFAP+ astrocytes (data not shown). We examined IL-11R $\alpha$ expression in these cultures, and found that the receptor was expressed by oligodendroglia, as we had found in our immunohistochemical studies, although in vitro the pattern of expression appeared to include quite immature cells. Immunoreactivity localized to a high percentage of the immature A2B5+ oligodendrocytes in these cultures, (Fig. $4 c, d$ ), whereas a significantly smaller percentage of $\mathrm{O} 4+$ cells were IL$11 \mathrm{R} \alpha+$ (Fig. $4 c, e$ ), and still less IL-11R $\alpha$ staining was present in the CNPase+ oligodendrocyte population (Fig. $4 c, f$ ). We did not observe expression of IL-11R $\alpha$ in GFAP+ astrocytes (data not shown).

To determine the functional effects of IL-11, we performed assays that focused on cell number, viability, mitosis, and maturation (Fig. 5). Primary human fetal oligodendrocyte-enriched cultures were treated with recombinant human IL-11 (1-100 $\mathrm{ng} / \mathrm{ml})$ at plating, and were allowed to grow and mature as above before being fixed for immunostaining, cell counting, and morphometry, or harvested for RNA (real-time PCR) or protein (Western blotting). Initially, we performed cell counting of immunofluorescently labeled cultures, and these experiments revealed that IL-11 treatment was associated with an increase in the number of oligodendrocytes: we found that there were significantly more cells per field positive for A2B5, O4, or CNPase in treated cultures than in controls (Fig. $5 a-c$ ). In contrast, we did not observe a significant increase in the number of GFAP+ cells in IL-11-treated cultures (data not shown). Effects on oligodendrocytes were statistically significant at a treatment concentration of $10 \mathrm{ng} / \mathrm{ml}$ IL-11 (Fig. 5a,b). An additional increase in the number of CNPase+ oligodendrocytes was apparent at a concentration of $100 \mathrm{ng} / \mathrm{ml}$, together with a small increase in the number of $\mathrm{O} 4+$ cells (Fig. $5 c$ ). 
Similar effects were also observed in cultures allowed to grow for longer periods (10 d) (data not shown).

We next performed experiments to determine the extent to which the effects of IL-11 on oligodendrocyte number were attributable to changes in cell maturation, viability, and/or proliferation (Fig. $5 d-f$ ). IL-11 was used in these experiments at a concentration of $10 \mathrm{ng} / \mathrm{ml}$, based on the results of our dose-response studies and previous reports from other systems (Fig. 5c) (see Materials and Methods). To investigate potential effects on oligodendrocyte maturation, we examined expression of the cyclin kinase inhibitor p2 ${ }^{\mathrm{CIP} 1}$, which has been strongly implicated in the establishment of an oligodendrocyte differentiation program (Ghiani et al., 1999; Zezula et al., 2001). Using real-time PCR and Western blotting, we found that IL-11 treatment was associated with a significant increase in $\mathrm{p} 21^{\mathrm{CIP} 1}$ at the RNA and protein levels (Fig. $5 d, e$ ). These data were supported by real-time PCR studies examining myelin gene expression, which showed

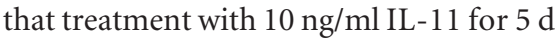
was associated with an increase in of $\sim 50 \%$ in the expression of both CNPase and MBP in IL-11-treated cultures compared with controls. Statistical analysis of these results showed that they were significant (CNPase, $p<0.05$; MBP, $p<$ 0.001 , Student's $t$ test) (data not shown). In addition, we found that oligodendroglia in cultures exposed to $10 \mathrm{ng} / \mathrm{ml}$ IL-11 were more extensively arborized than untreated controls, displaying a significant increase in process branching. Quantitation of the oligodendroglial morphological complexity using fractal analysis demonstrated that this difference was significant $(p<0.001)$ (data not shown).

We also investigated effects on oligodendrocyte viability, using staining for the apoptosis marker TUNEL. These studies showed that IL-11 treatment was associated with a significant reduction in apoptosis in treated cultures, as assessed by the number of TUNEL + cells per field (Fig. $5 f$ ). Finally, we examined effects of IL-11 on cell proliferation, using BrdU labeling and immunostaining for Ki-67. These experiments showed that, in contrast to its effects on maturation and viability, IL-11 had no significant impact on the number of mitotic cells in our cultures. Staining experiments for Ki-67 antigen indicated that $\sim 3-5 \%$ of cells in these cultures were proliferating, and that this number was not significantly affected by IL-11 treatment (data not shown).

In addition to these experiments, we also performed studies to compare the effects of IL-11 to those of LIF, another cytokine of the gp130 family that has previously been implicated in oligodendrocyte protection and myelin formation in rodent systems
(Mayer et al., 1994; Gard et al., 1995; Butzkueven et al., 2002; Ishibashi et al., 2005; Vanderlocht et al., 2006). Primary human fetal oligodendrocyte-enriched cultures were treated at plating with $10 \mathrm{ng} / \mathrm{ml}$ recombinant IL-11 or LIF, and allowed to grow and mature as above before being fixed, stained, and analyzed. Interestingly, the results of these studies indicated that LIF did not have a significant impact on the number of oligodendrocyte lineage cells, or GFAP + cells, in our human cultures at the concentrations tested (data not shown). Interestingly, we did find that LIF potentiated the extent of oligodendroglial arborization, although this effect was weaker than that observed in response to IL-11 ( $p<0.01)$ (data not shown). Together, the results of these studies suggested that IL-11 potentiates the viability and matura- 
a.

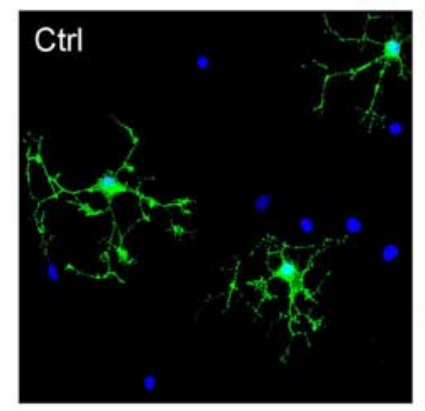

O4/DAPI

\begin{tabular}{|c|c|c|c|c|}
\hline$b$. & & Ctrl & IL-11 10ng/ml & $\mathrm{P}$ \\
\hline \multirow{3}{*}{ 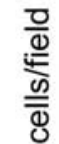 } & & $14.8+/-1.5$ & $23.5+/-2.2$ & $<0.01$ \\
\hline & 04+ & $13.2+/-0.8$ & $21.7+/-1.7$ & $<0.01$ \\
\hline & CNP+ & $11.0+/-1.3$ & $17.8+/-0.6$ & $<0.01$ \\
\hline
\end{tabular}

c.

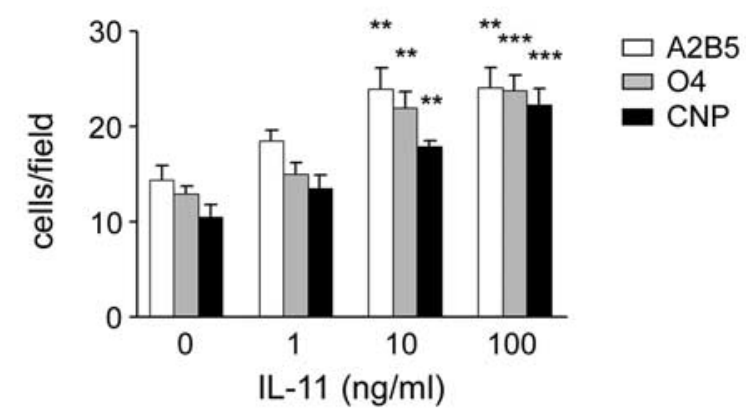

d.

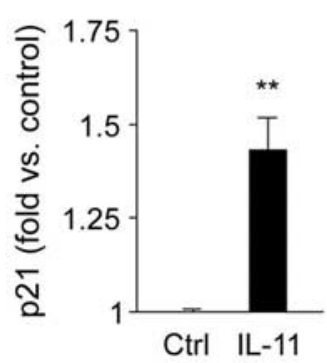

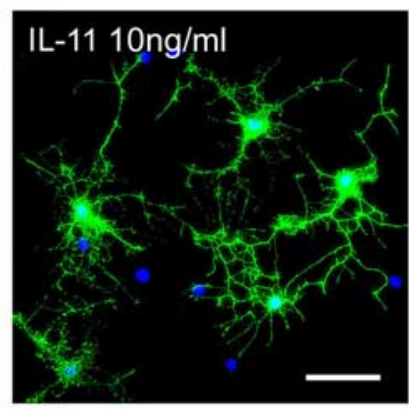

e. $\quad \mathrm{Ctrl} \quad \mathrm{IL}-11$

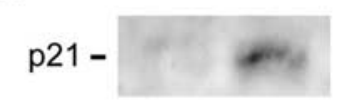

f.

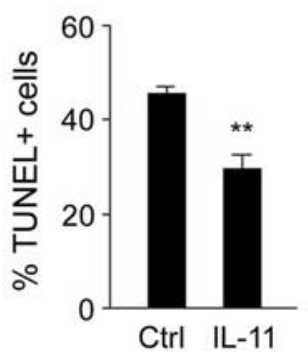

Figure 5. IL-11 potentiates the survival and maturation of primary human oligodendroglia. Primary human fetal spinal cord cultures enriched for oligodendrocytes were allowed to grow and mature for $5 \mathrm{~d}$ before being fixed for immunofluorescence and morphometry or harvested to generate RNA or protein extracts. Some cultures were treated with recombinant human IL-11 (1-100 ng/ml) at plating, and cytokine was allowed to remain in the medium throughout the experiment. $\boldsymbol{a}-\boldsymbol{c}$, More cells per field were positive for the oligodendrocyte markers A2B5, 04, and CNPase in IL-11-treated cultures than in controls. Effects on oligodendrocytes were statistically significant at a treatment concentration of $10 \mathrm{ng} / \mathrm{ml} \mathrm{IL-11}(\boldsymbol{a}, \boldsymbol{b})$. An additional increase in the number of CNPase + oligodendrocytes was apparent at a concentration of $100 \mathrm{ng} / \mathrm{ml}$, together with a small increase in $04+$ cells (c). Based on these results, additional analyses of IL-11 effects were performed using a dose of $10 \mathrm{ng} / \mathrm{ml}$. $\boldsymbol{d}, \boldsymbol{e}, \mathrm{IL}-11$ treatment was associated with significant potentiation of oligodendrocyte maturation, as assessed by expression of the cyclin kinase inhibitor $\mathrm{P} 21^{\mathrm{CIP}}$ at the RNA level by real-time PCR $(\boldsymbol{d})$ and at the protein level by Western blotting $(\boldsymbol{e})$. IL-11 treatment was also associated with significantly reduced levels of apoptosis in treated cultures, as assessed by staining for the apoptosis marker TUNEL (f). In contrast, no significant change in cell proliferation was observed (BrdU labeling, Ki-67 staining) (data not shown). Scale bar, $30 \mu \mathrm{m} .{ }^{* * *} p<0.001,{ }^{* *} p<0.01$, results obtained using one-way ANOVA followed by Bonferroni's post test $(\boldsymbol{b}, \boldsymbol{c})$, or Student's $t$ test $(\boldsymbol{d}, \boldsymbol{f})$. Data are representative of three separate experiments on oligodendrocytes from three different cords. Error bars indicate SEM. Ctrl, Control.

tion of human oligodendrocytes, and that its effects are more potent than those of LIF.

\section{IL-11 potentiates myelin formation in CNS cocultures}

To determine whether the effects of IL-11 on oligodendrocytes are associated with changes in their ability to form myelin, we conducted experiments using myelinating rodent CNS cocultures (Fig. 6). These were established from mouse (E14.5 DRG) and rat ( $\mathrm{P} 1$ cerebral cortex) tissues using published methods (Caporaso and Chao, 2001; Chan et al., 2004; Taveggia et al., 2005) and as outlined in Materials and Methods. Preliminary immunostaining experiments suggested that any effects of IL-11 in these cultures would result predominantly from signaling in oligodendrocytes (see Materials and Methods). Myelination was initiated by adding TrkA-Fc $(1 \mu \mathrm{g} / \mathrm{ml})$ to neutralize the activity of NGF and promote myelin formation, which occurred over a period of 14 d. Recombinant IL-11 (1-100 ng/ml) was added after oligodendrocyte purification, and supplemented in the medium every other day during myelination. After $14 \mathrm{~d}$, cells were fixed, immunostained for markers specific for axons [high-molecular-weight neurofilament (NF)] and myelin (MBP), and subjected to quantitative analysis. Both control and IL-11-treated cultures contained linear $\mathrm{MBP}+$ segments that extended along NF+ axons, and we found that IL-11-treated cultures contained significantly more of these segments than controls (Fig. 6a,b). Quantitation and statistical analysis showed that the effect of IL-11 was statistically significant at a treatment concentration of $10 \mathrm{ng} / \mathrm{ml}$, and an additional increase in the number of segments per field was apparent at a concentration of $100 \mathrm{ng} / \mathrm{ml}$ (Fig. 6b). Based on these results, subsequent analysis was performed using cultures treated with an IL-11 concentration of $10 \mathrm{ng} / \mathrm{ml}$. To determine whether IL-11 accelerated the formation of MBP+ segments, we examined cultures at earlier time points after addition of TrkA-Fc (7-10 d). Interestingly, these experiments showed that, although IL-11 potentiated the number of segments per field, it did not appear to affect the timing of these events: $\mathrm{MBP}+$ segments were not observed any earlier in treated cultures than controls (data not shown). Examination at a higher magnification showed that, in both treated cultures and controls, $\mathrm{MBP}+$ segments surrounded and appeared to ensheath NF+ axons, a pattern consistent with myelin formation (Fig. $6 c$ ). To examine these structures more closely, we used electron microscopy, and these studies confirmed the presence of compact myelin in both control and IL-11-treated cultures (Fig. 6d). Interestingly, although IL-11 treatment was associated with an increase in the number of myelin segments, it did not appear to affect myelin thickness (Fig. $6 d$ ), and we also found that normal paranodes containing septate junctions were present in both control and treated cultures (example illustrated in Fig. 6e). Together, these findings show that IL-11 potentiates myelin formation in CNS cocultures. They further suggest that this effect results from an increase in the number of myelin segments formed, and that the structure and/or organization of these segments is otherwise unchanged.

\section{Discussion}

Studies on the pathology of MS tissue suggest that there are at least two types of lesions in the disease in which remyelination eventually fails: those in which OPCs are present in insufficient numbers, implying failure of survival or recruitment (Prineas et al., 1993; Niehaus et al., 2000), and those in which OPCs are present but unable to complete the myelination program (Wolswijk, 1998; Chang et al., 2002). Recent work has improved our knowledge of the factors that control OPC survival and differen- 
tiation, and myelin formation, and suggest that local conditions within the lesion play an important role in these events (Lubetzki et al., 2005). Consistent with a role in remyelination, the growth factors PDGF-AA, FGF-2, and IGF-1 have been shown to potentiate the proliferation, $\mathrm{mi}$ gration, and differentiation of cultured adult OPCs (McMorris et al., 1986; Raff et al., 1988; Armstrong et al., 1990; Hsieh et al., 2004), although only PDGF-driven progenitor proliferation has been convincingly demonstrated in vivo (Calver et al., 1998; Fruttiger et al., 1999). Increased expression of these factors has also been demonstrated in experimental models of remyelination (Hinks and Franklin, 1999). Cytokines (TGF $\beta 1, \mathrm{TNF} \alpha$ ), chemokines (CXCL1), extracellular matrix components (high-molecular-weight glycosaminoglycans), and developmental cues (Jagged 1) have also been shown to regulate the behavior of fetal or perinatal OPCs (McKinnon et al., 1993; Wu et al., 2000; Arnett et al., 2001; John et al., 2002; Back et al., 2005), and to be expressed in MS lesions (Cannella and Raine, 1995; John et al., 2002; Back et al., 2005; Omari et al., 2006).

A reactive astroglial response is a prominent feature of the lesions of MS (Raine, 1997), and reactive astrocytes comprise the most abundant cellular component of the lesion environment (Holley et al., 2003). Studies using transgenic animals have demonstrated that these cells are intimately involved in regulating inflammation and repair after insult or injury to the CNS (Liedtke et al., 1996; Bush et al., 1999), and they have been shown to express several factors believed to regulate OPC behavior (Komoly et al., 1992; Wolswijk and Noble, 1992; Gard et al., 1995; Redwine and Armstrong, 1998; Wu et al., 2000; John et al., 2002; Back et al., 2005). Cytokines for which the evidence of direct involvement in a reactive astrogliosis is most compelling include IL- $1 \beta, \operatorname{TNF} \alpha$, IFN $\gamma$, and TGF $\beta 1$, and each appears to fulfill a different role in the response, inducing a specific pattern of gene expression and a resultant functional effect (for review, see John et al., 2003). Of these, IL- $1 \beta$ and TGF $\beta 1$ stand out as being particularly interesting in the context of the MS lesion. IL- $1 \beta$ is associated with a proinflammatory role early in the course of CNS disease and is believed to be central to the induction of a reactive astroglial response (Herx and Yong, 2001). IL-1 $\beta$ is expressed in acute and chronic-active plaques, by macrophages within the lesion center and microglia at the lesion edge (Brosnan et al., 1994), and its levels in the CSF of MS patients correlate with disease activity (Hauser et al., 1990). Interestingly, however, recent work has also highlighted the role of IL- $1 \beta$ in the regenerative process in the CNS (Mason et al., 2001). a.

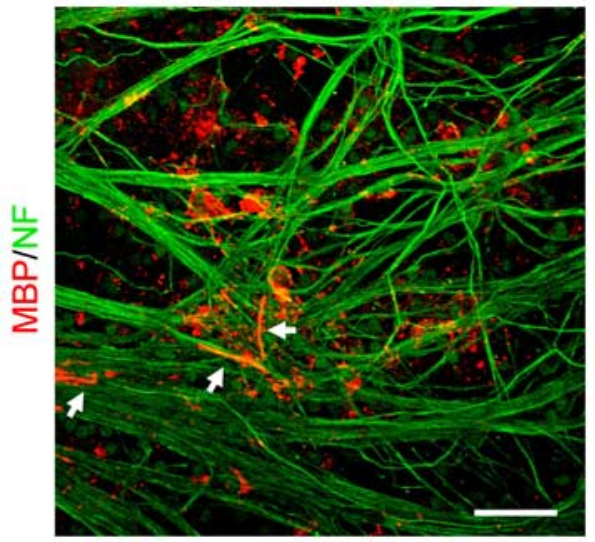

b.

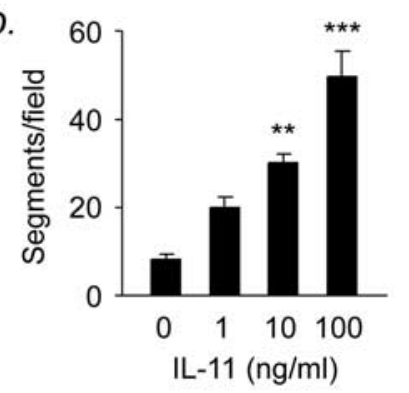

e.

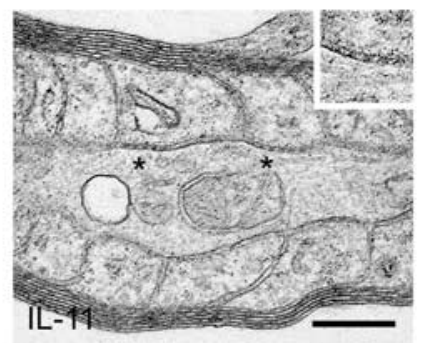

C.
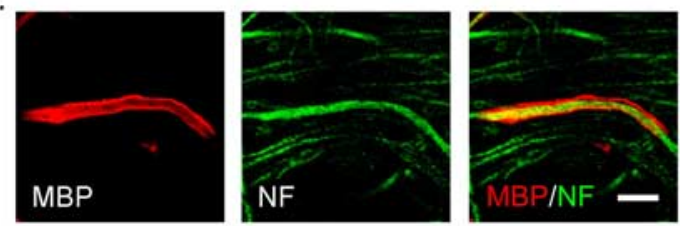

d.
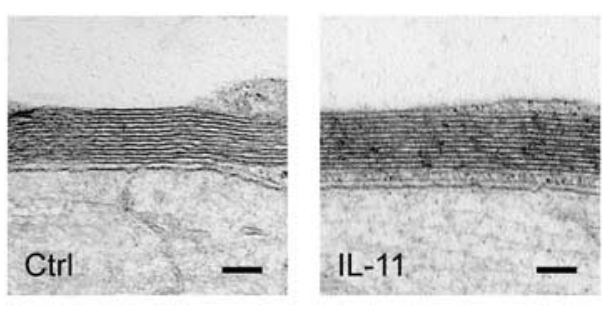

Figure 6. IL-11 potentiates myelin formation in vitro. Cocultures of mouse E14.5 DRG neurons and rat P1 cortical oligodendroglia were allowed to myelinate over a period of $14 \mathrm{~d}$. Recombinant IL-11 (1-100 ng/ml) was added after oligodendrocyte purification and supplemented in the medium every other day throughout the experiment. $\boldsymbol{a}$, Confocal microscopy: Z-series projections of cultures immunostained for myelin (MBP; red) and axons (NF; green). Linear MBP + segments can be observed extending along NF+ axons (arrows). $\boldsymbol{a}, \boldsymbol{b}$, More segments were present in IL-11-treated cultures than controls (Ctrl). $\boldsymbol{b}$, Statistical analysis showed that this difference was significant at a dose of $10 \mathrm{ng} / \mathrm{ml}$, with an additional effect observed at $100 \mathrm{ng} / \mathrm{ml}$. Based on these results, additional analyses of IL-11 effects were performed using a dose of $10 \mathrm{ng} / \mathrm{ml}$. c shows a higher power view of part of $\boldsymbol{a}$ (asterisk). An MBP + segment surrounds and appears to ensheath an NF + axon, a pattern consistent with myelin formation. $\boldsymbol{d}$, Examination using electron microscopy confirmed the presence of compact myelin in both IL-11-treated cultures and controls. Although IL-11 treatment was associated with an increase in the number of myelin segments, it did not affect myelin thickness. $\boldsymbol{e}$, Normal-appearing paranodes containing septate junctions (marked by asterisks) were present in both control and treated cultures (example shown is from an IL-11-treated culture). Septate junctions are also shown at a higher magnification for clarity (inset). Scale bars: $\boldsymbol{a}, 40 \mu \mathrm{m} ; \boldsymbol{c}, 5 \mu \mathrm{m} ; \boldsymbol{d}, 100 \mathrm{~nm} ; \boldsymbol{e}, 250 \mathrm{~nm}$. In $\boldsymbol{b},{ }^{* * *} p<0.001,{ }^{* *} p<$ 0.01 , one-way ANOVA followed by Bonferroni's post test. Data are representative of three separate experiments on three independent cultures. Error bars indicate SEM.

Conversely, based on available evidence, the role of TGF $\beta 1$ may be somewhat different. Expression of this cytokine by astrocytes and microglia has been demonstrated in animal models of CNS trauma, inflammation, and MS, and it is known that astrocytes both produce and respond to TGF $\beta 1$ (Logan et al., 1994; Cannella and Raine, 1995; Peress et al., 1996). TGF $\beta 1$ appears to serve two discrete functions: first, as a negative regulator of inflammation (Shull et al., 1992), and second, as a key player in the injury response (Border and Noble, 1994; Wyss-Coray et al., 1997; Singer and Clark, 1999).

In the current study, we investigated potential links between a 
reactive astrogliosis and MS lesion repair using a microarraybased approach, and identified the gp130 cytokine IL-11 as an astrocyte-derived factor that may play a positive role in regulating oligodendrocyte survival and maturation, and myelin formation. We found that IL-11 was induced in response to IL- $1 \beta$ and TGF $\beta 1$ in an in vitro model of a reactive astrogliosis, and analysis of brain tissue from MS patients supported and extended these data, confirming IL-11 expression by reactive astrocytes in vivo and indicating that it localized predominantly to the border of both active and silent MS lesions. The receptor for IL-11, IL$11 \mathrm{R} \alpha$, localized to oligodendroglia with a variety of morphologies, including interfascicular oligodendrocytes and less mature PDGFR $\alpha+$ cells. In comparison, in primary human cultures, we found that oligodendrocytes also expressed IL-11R $\alpha$, although the pattern of expression in vitro included a higher proportion of more immature cells. We suspect that this difference may be a reflection of the different oligodendrocyte populations in the CNS tissue being examined in the two studies. It might be reasonable to expect myelinated adult human CNS tissue to contain a higher proportion of mature oligodendrocytes, and fewer progenitors, than the fetal CNS tissue used in our in vitro studies.

To better understand the effects of IL-11 on oligodendrocytes, we performed functional studies in primary human cultures. The results of these experiments showed that IL-11 enhances oligodendrocyte survival and maturation. We also found that, at the concentrations tested, these effects of IL-11 were more potent than those of LIF, another cytokine of the gp130 family that has previously been implicated in oligodendrocyte protection and myelin formation in rodent systems (Mayer et al., 1994; Gard et al., 1995; Butzkueven et al., 2002), although we cannot rule out potential effects of higher or lower concentrations of LIF than were tested in this study (for example, see Ishibashi et al., 2005). In addition, we demonstrated that IL-11 treatment was associated with significantly potentiated myelin formation in CNS cocultures. This effect appeared to result from an increase in the number of myelin segments formed in IL-11-treated cultures. Interestingly, the timing of myelin formation, and the structure and/or organization of myelin segments appeared otherwise unchanged when compared with controls.

The role of astrocytes in regulating cell differentiation and maturation is currently being explored in research into neural progenitor cells in the adult CNS. Work performed in this field has shown that astrocytes provide key cues in the fate specification of these cells (Song et al., 2002), and suggests that astrocytes produce different signals for lineage-specific differentiation in different environments and regions within the CNS. Based on our data and results from other groups, it might be interesting to extrapolate this hypothesis to include the role of astrocytes in regulating protection and repair in pathological conditions in the adult. We suggest that studies into the functional properties of reactive astroglia, and how they change as lesions age, may represent a promising area of research into MS.

The gp130 family is of increasing interest in immunology and neurobiology because of the ability of specific members to function as modulators of proliferation, differentiation, and/or survival for multiple cell lineages (Heinrich et al., 2003). All family members act via receptor complexes containing gp130. IL-6, IL$11, \mathrm{CNTF}$, and possibly CT-1 act on target cells through interactions with a ligand specific receptor and induce signaling by association of this receptor with either a gp130/gp130 homodimer (IL-6 and IL-11), or a gp130/LIFR heterodimer (CNTF) (Heinrich et al., 1998). In contrast, LIF binds directly to the LIFR, with subsequent formation of a LIFR/gp130 heterodimer. Minimal information is available concerning the functions of IL-11 and IL-11R $\alpha$ in the postnatal CNS, although more is known about the effects of IL-11 signaling in development and in other systems. In the developing CNS, IL-11 has been shown to induce both neuronal differentiation in a hippocampal cell line (Mehler et al., 1993), and astrocytic differentiation of mouse neuroepithelial cells (Yanagisawa et al., 2000), and it shares this latter property with family members including LIF and CNTF (Hughes et al., 1988; Koblar et al., 1998). In other systems, it is known to regulate hematopoiesis and is a potent stimulator of megakaryocytopoiesis (Teramura et al., 1992). It also has immunoregulatory effects and inhibits cytokine production in activated macrophages (Trepicchio et al., 1997). In addition, it has been shown to stimulate both bone formation and resorption (Takeuchi et al., 2002). Finally, IL-11 signaling is required for the normal development of implantation and survival to birth (Robb et al., 1998).

Studies in the postnatal CNS have indicated that a number of gp130 family cytokines, including IL-6, play a significant role in regulating inflammation in the CNS, whereas other members, particularly those that include LIFR as part of their signaling complex such as LIF and CNTF, are involved in the regulation of regeneration. Thus, mice deficient for IL-6 are resistant to the model of MS, experimental autoimmune encephalomyelitis (EAE), and the mechanism involved appears to be immunoregulatory (Mendel et al., 1998). Conversely, LIF is protective in EAE, and the mechanism involved is different. The inflammatory infiltrates typical of EAE are not reduced after LIF treatment and the effect of this cytokine appears to be directed at the sparing of tissue elements, including oligodendrocytes (Butzkueven et al., 2002). Complementary studies have also implicated astrocytederived LIF in oligodendrocyte maturation and myelin formation in the developing CNS, and have suggested that this may represent a novel approach to treating demyelinating disease (Mayer et al., 1994; Gard et al., 1995; Ishibashi et al., 2005). Our in vitro findings indicate that the effects of IL-11 on human oligodendrocytes may be more potent than those of LIF at the concentrations tested, and it will be interesting to determine which of these cytokines (or a combination of both) is more effective in potentiating oligodendrocyte survival and maturation, and myelin formation, in vivo.

To date, current treatments for MS are targeted at controlling the immune response and downregulating inflammation and new lesion formation, and very few options are available that promote regeneration and remyelination. Novel factors that potentiate oligodendrocyte survival or maturation, and in particular the formation of myelin, are therefore of particular interest. Our ongoing studies in this area are directed at determining whether the effects of IL-11 on myelin formation are attributable to maturational or morphological effects, and/or to potentiation of oligodendrocyte survival. Our data suggesting that IL-11 regulates the extent of myelin formation in vitro, but not its timing, may be relevant in this context. We also plan to characterize in more detail the cells expressing IL-11 and its receptor in vivo and in vitro. Finally, examination of the effects of IL-11 in an animal model is a logical extension of the studies presented in the current paper, and this is an area we are currently exploring.

Together, our data indicate that IL-11 is expressed by reactive astrocytes and that its actions on oligodendrocytes have the potential to positively regulate the survival and the maturation of these cells and their myelinating function. On the basis of our findings, we suggest that the IL-11/IL-11R $\alpha$ pathway may potentially be relevant to oligodendrocyte protection and/or 
myelin formation in inflammatory demyelinating disorders within the CNS.

\section{References}

Adachi T, Takanaga H, Kunimoto M, Asou H (2005) Influence of LIF and BMP-2 on differentiation and development of glia cells in primary cultures of embryonic rat cerebral hemisphere. J Neurosci Res 79:608-615.

Armstrong R, Friedrich Jr VL, Holmes KV, Dubois-Dalcq M, Armstrong R, Friedrich Jr VL, Holmes KV, Dubois-Dalcq M (1990) In vitro analysis of the oligodendrocyte lineage in mice during demyelination and remyelination. J Cell Biol 111:1183-1195.

Arnett HA, Mason J, Marino M, Suzuki K, Matsushima GK, Ting JP (2001) TNF alpha promotes proliferation of oligodendrocyte progenitors and remyelination. Nat Neurosci 4:1116-1122.

Back SA, Tuohy TMF, Chen H, Wallingford N, Craig A, Struve J, Luo NL, Banine F, Liu Y, Chang A, Trapp BD, Bebo BF, Rao MS, Sherman LS (2005) Hyaluronan accumulates in demyelinated lesions and inhibits oligodendrocyte progenitor maturation. Nat Med 11:966-972.

Baranzini SE, Elfstrom C, Chang SY, Butunoi C, Murray R, Higuchi R, Oksenberg JR (2000) Transcriptional analysis of multiple sclerosis brain lesions reveals a complex pattern of cytokine expression. J Immunol 165:6576-6582.

Barcellos LF, Thomson G, Carrington M, Schafer J, Begovich AB, Lin P, Xu XH, Min BQ, Marti D, Klitz W (1997) Chromosome 19 single-locus and multilocus haplotype associations with multiple sclerosis. Evidence of a new susceptibility locus in Caucasian and Chinese patients. JAMA 278:1256-1261.

Border WA, Noble NA (1994) Transforming growth factor beta in tissue fibrosis. N Engl J Med 331:1286-1292.

Brosnan CF, Battistini L, Raine CS, Dickson DW, Casadevall A, Lee SC (1994) Reactive nitrogen intermediates in human neuropathology: an overview. Dev Neurosci 16:152-161.

Brück W, Stadelmann C (2005) The spectrum of multiple sclerosis: new lessons from pathology. Curr Opin Neurol 18:221-224.

Brück W, Kuhlmann T, Stadelmann C (2003) Remyelination in multiple sclerosis. J Neurol Sci 206:181-185.

Bush TG, Puvanachandra N, Horner CH, Polito A, Ostenfeld T, Svendsen CN, Mucke L, Johnson MH, Sofroniew MV (1999) Leukocyte infiltration, neuronal degeneration, and neurite outgrowth after ablation of scarforming, reactive astrocytes in adult transgenic mice. Neuron 23:297-308.

Butzkueven H, Zhang JG, Soliu-Hanninen M, Hochrein H, Chionh F, Shipham KA, Emery B, Turnley AM, Petratos S, Ernst M, Barlett PF, Kilpatrick TJ (2002) LIF receptor signaling limits immune-mediated demyelination by enhancing oligodendrocyte survival. Nat Med 8:613-619.

Calver AR, Hall AC, Yu WP, Walsh FS, Heath JK, Betsholtz C, Richardson WD (1998) Oligodendrocyte population dynamics and the role of PDGF in vivo. Neuron 20:869-882.

Cannella B, Raine CS (1995) The adhesion molecule and cytokine profile of multiple sclerosis lesions. Ann Neurol 37:424-435.

Caporaso GL, Chao MV (2001) Telomerase and oligodendrocyte differentiation. J Neurobiol 49:224-234.

Chan JR, Watkins TA, Cosgaya JM, Zhang C, Chen L, Reichardt LF, Shooter EM, Barres BA (2004) NGF controls axonal receptivity to myelination by Schwann cells or oligodendrocytes. Neuron 43:183-191.

Chang A, Tourtellotte WW, Rudick R, Trapp BD (2002) Premyelinating oligodendrocytes in chronic lesions of multiple sclerosis. N Engl J Med 346:165-173.

Delhase M, Hayakawa M, Chen Y, Karin M (1999) Positive and negative regulation of Ikappa B kinase activity through IKK beta subunit phosphorylation. Science 284:309-313.

Einheber S, Hannocks MJ, Metz CN, Rifkin DB, Salzer JL (1995) Transforming growth factor-beta 1 regulates axon/Schwann cell interactions. J Cell Biol 129:443-458.

Enomoto H, Furuichi T, Zanma A, Yamana K, Yoshida C, Sumitani S, Yamamoto H, Enomoto-Iwamoto M, Iwamoto M, Komori T (2004) Runx2 deficiency in chondrocytes causes adipogenic changes in vitro. J Cell Sci 117:417-425.

Ernst M, Jenkins BJ (2004) Acquiring signalling specificity from the cytokine receptor gp130. Trends Genet 20:23-32.

Faulkner JR, Herrmann JE, Woo MJ, Tansey KE, Doan NB, Sofroniew MV
(2004) Reactive astrocytes protect tissue and preserve function after spinal cord injury. J Neurosci 24:2143-2155.

Franklin RJ (2002) Why does remyelination fail in multiple sclerosis? Nat Rev Neurosci 3:705-714.

Frohman EM, Racke MK, Raine CS (2006) Multiple sclerosis-the plaque and its pathogenesis. N Engl J Med 354:942-955.

Fruttiger M, Karlsson L, Hall AC, Abramsson A, Calver AR, Bostrom H, Willetts K, Bertold CH, Heath JK, Betsholtz C, Richardson WD (1999) Defective oligodendrocyte development and severe hypomyelination in PDGF-A knockout mice. Development 126:457-467.

Gard AL, Burrell MR, Pfeiffer SE, Rudge JS, Williams II WC (1995) Astroglial control of oligodendrocyte survival mediated by PDGF and leukemia inhibitory factor-like protein. Development 121:2187-2197.

Ghiani CA, Eisen AM, Yuan X, DePinho RA, McBain CJ, Gallo V (1999) Neurotransmitter receptor activation triggers p27(Kip1)and p21(CIP1) accumulation and G1 cell cycle arrest in oligodendrocyte progenitors. Development 126:1077-1090.

Green AJ, Barcellos LF, Rimmler JB, Garcia ME, Caillier S, Lincoln RR, Bucher P, Pericak-Vance MA, Haines JL, Hauser SL, Oksenberg JR (2001) Sequence variance in the transforming growth factor- $\beta 1$ (TGFB1) gene and multiple sclerosis susceptibility. J Neuroimmunol 116:116-124.

Hauser SL, Doolittle TH, Lincoln R, Brown RH, Dinarello CA (1990) Cytokine accumulations in CSF of multiple sclerosis patients: frequent detection of interleukin-1 and tumor necrosis factor but not interleukin-6. Neurology 40:1735-1739.

Heinrich P, Behermann I, Müller-Newen G, Schaper F, Graeve L (1998) Interleukin-6-type cytokine signaling through the gp130/Jak/STAT pathway. Biochem J 334:297-314.

Heinrich PC, Behrmann I, Hann S, Hermanns HM, Müller-Newen G, Schaper F (2003) Principle of interleukin-6 type cytokine signaling and its regulation. Biochem J 374:1-20.

Herx LM, Yong VW (2001) Interleukin-1 beta is required for the early evolution of reactive astrogliosis following CNS lesion. J Neuropathol Exp Neurol 60:961-971.

Hinks GL, Franklin JM (1999) Distinctive patterns of PDGF-A, FGF-2, IGF-1, and TGF- $\beta 1$ gene expressing during remyelination of experimentally-induced spinal cord demyelination. Mol Cell Neurosci 14:153-168.

Holley GE, Gveric D, Newcombe J, Cuzner ML, Gutowski NJ (2003) Astrocyte characterization in the multiple sclerosis glial scar. Neuropathol Appl Neurobiol 29:434-444.

Hsieh J, Aimone JB, Kaspar BK, Kuwabara T, Nakashima K, Gage FH (2004) IGF-1 instructs multipotent adult neural progenitor cells to become oligodendrocytes. J Cell Biol 164:111-122.

Hughes SM, Lillien LE, Raff MC, Rohrer H, Sendtner M (1988) Ciliary neurotrophic factor induces type- 2 astrocyte differentiation in culture. $\mathrm{Na}$ ture 335:70-73.

Ishibashi T, Dakin KA, Stevens B, Lee PR, Kozlov SV, Stewart CL, Fields RD (2005) Astrocytes promote myelination in response to electrical impulses. Neuron 49:823-832.

John GR, Shankar SL, Shafit-Zagardo B, Massimi A, Lee SC, Raine CS, Brosnan CF (2002) Multiple sclerosis: re-expression of a developmental pathway that restricts oligodendrocyte maturation. Nat Med 8:1115-1121.

John GR, Lee SC, Brosnan CF (2003) Cytokines: powerful regulators of glial cell activation. Neuroscientist 9:10-22.

Kieseier BC, Hemmer B, Hartung HP (2005) Multiple sclerosis-novel insights and new therapeutic strategies. Curr Opin Neurol 18:211-220.

Koblar SA, Turnley AM, Classon BJ, Reid KL, Ware CB, Cheema SS, Murphy M, Bartlett PF (1998) Neural precursor differentiation into astrocytes requires signaling through the leukemia inhibitory factor receptor. Proc Natl Acad Sci USA 95:3178-3181.

Komoly S, Hudson LD, Webster HD, Bondy CA (1992) Insulin-like growth factor I gene expression is induced in astrocytes during experimental demyelination. Proc Natl Acad Sci USA 89:1894-1898.

Liedtke W, Edelmann W, Bieri PL, Chiu FC, Cowan NJ, Kucherlapati R, Raine CS (1996) GFAP is necessary for the integrity of CNS white matter architecture and long-term maintenance of myelination. Neuron 17:607-615.

Linker RA, Maurer M, Gaupp S, Martini R, Holtmann B, Giess R, Rieckmann P, Lassmann H, Toyka KV, Sendtner M, Gold R (2002) CNTF is a major 
protective factor in demyelinating CNS disease: a neurotrophic cytokine as modulator in neuroinflammation. Nat Med 8:620-624.

Liu J, Zhao ML, Brosnan CF, Lee SC (1996) Expression of type II nitric oxide synthase in primary human astrocytes and microglia: role of IL-1beta and IL-1 receptor antagonist. J Immunol 157:3569-3576.

Liu JSH, John GR, Sikora A, Lee SC, Brosnan CF (2000) Modulation of interleukin- $1 \beta$ and tumor necrosis factor- $\alpha$ signaling by $\mathrm{P} 2$ purinergic receptors in human fetal astrocytes. J Neurosci 20:5292-5299.

Logan A, Berry M, Gonzalez AM, Frautschy SA, Sporn MB, Baird A (1994) Effects of transforming growth factor beta 1 on scar production in the injured central nervous system of the rat. Eur J Neurosci 6:355-363.

Lubetzki C, Williams A, Stankoff B (2005) Promoting repair in multiple sclerosis: problems and prospects. Curr Opin Neurol 18:237-244.

Mason JL, Suzuki K, Chaplin DD, Matsushima GK (2001) Interleukin-1 $\beta$ promotes repair of the CNS. J Neurosci 21:7046-7052.

Mayer M, Bhakoo K, Noble M (1994) Ciliary neurotrophic factor and leukemia inhibitory factor promote the generation, maturation and survival of oligodendrocytes in vitro. Development 120:143-153.

McKinnon RD, Piras G, Ida Jr JA, Dubois-Dalcq M (1993) A role for TGFbeta in oligodendrocyte differentiation. J Cell Biol 121:1397-1407.

McMorris FA, Smith TM, DeSalvo S, Furlanetto RW (1986) Insulin-like growth factor I/somatomedin C: a potent inducer of oligodendrocyte development. Proc Natl Acad Sci USA 83:822-826.

Mehler MF, Rozental R, Dougherty M, Spray DC, Kessler JA (1993) Cytokine regulation of neuronal differentiation of hippocampal progenitor cells. Nature 362:62-65.

Mendel I, Katz A, Kozak N, Ben-Nun A, Revel M (1998) Interleukin-6 functions in autoimmune encephalomyelitis: a study in gene-targeted mice. Eur J Immunol 28:1727-1737.

Niehaus A, Shi J, Grzenkowski M, Diers-Fenger M, Archelos J, Hartung HP, Toyka K, Bruck W, Trotter J (2000) Patients with active relapsingremitting multiple sclerosis synthesize antibodies recognizing oligodendrocyte progenitor cell surface protein: implications for remyelination. Ann Neurol 48:362-371.

Omari KM, John G, Lango R, Raine CS (2006) Role for CXCR2 and CXCL1 on glia in multiple sclerosis. Glia 53:24-31.

Peress NS, Perillo E, Seidman RJ (1996) Glial transforming growth factor (TGF)-beta isotypes in multiple sclerosis: differential glial expression of TGF-beta 1, 2 and 3 isotypes in multiple sclerosis. J Neuroimmunol 71:115-123.

Prineas JW, Barnard RO, Revesz T, Kwon EE, Sharer L, Cho ES (1993) Multiple sclerosis: pathology of recurrent lesions. Brain 116:681-693.

Raff MC, Lillien LE, Richardson WD, Burne JF, Noble MD (1988) Plateletderived growth factor from astrocytes drives the clock that times oligodendrocyte development in culture. Nature 333:562-565.

Raine CS (1997) Demyelinating diseases. In: Textbook of neuropathology (Davis RL, Robertson DM, eds), pp 243-287. Baltimore: Williams and Wilkins.

Redwine JM, Armstrong RC (1998) In vivo proliferation of oligodendrocyte progenitors expressing PDGFalphaR during early remyelination. J Neurobiol 37:413-428.

Robb L, Li R, Hartley L, Nandurkar HH, Koentgen F, Begley CG (1998) Infertility in female mice lacking the receptor for interleukin 11 is due to a defective uterine response to implantation. Nat Med 4:303-308.

Shull MM, Ormsby I, Kier AB, Pawlowski S, Diebold RJ, Yin M, Allen R, Sidman C, Proetzel G, Calvin D, Annunziata N, Doetschman T (1992) Targeted disruption of the mouse transforming growth factor-beta 1 gene results in multifocal inflammatory disease. Nature 359:693-699.
Singer AJ, Clark RA (1999) Cutaneous wound healing. N Engl J Med 341:738-746.

Smith KJ, Blakemore WF, McDonald WI (1981) The restoration of conduction by central remyelination. Brain 104:383-404.

Song H, Stevens CF, Gage FH (2002) Astroglia induce neurogenesis from adult neural stem cells. Nature 417:39-44.

Takeuchi Y, Watanabe S, Ishii G, Takeda S, Nakayama K, Fukumoto S, Kaneta Y, Inoue D, Matsumoto T, Harigaya K, Fujita T (2002) Interleukiin-11 as a stimulatory factor for bone formation prevents bone loss with advancing age in mice. J Biol Chem 277:49011-49018.

Taveggia C, Zanazzi G, Petrylak A, Yano H, Rosenbluth J, Einheber S, Xu X, Esper RM, Loeb JA, Shrager P, Chao MV, Falls DL, Role L, Salzer JL (2005) Neuregulin-1 type III determines the ensheathment fate of axons. Neuron 47:681-694.

Teramura M, Kobayashi S, Hoshino S, Oshimi K, Mizoguchi H (1992) Interleukin-11 enhances human megakaryocytopoiesis in vitro. Blood 79:327-331.

Trepicchio WL, Wang L, Bozza M, Dorner AJ (1997) IL-11 regulates macrophage effector function through the inhibition of nuclear factorkappaB. J Immunol 159:5661-5670.

Vanderlocht J, Hellings N, Hendriks JJ, Vandenabeele F, Moreels M, Buntinx M, Hoekstra D, Antel JP, Stinissen P (2006) Leukemia inhibitory factor is produced by myelin-reactive $\mathrm{T}$ cells from multiple sclerosis patients and protects against tumor necrosis factor-alpha-induced oligodendrocyte apoptosis. J Neurosci Res 83:763-774.

Wilson HC, Onischke C, Raine CS (2003) Human oligodendrocyte precursor cells in vitro: phonotypic analysis and differential response to growth factors. Glia 44:153-165.

Wolswijk G (1998) Chronic stage multiple sclerosis lesions contain a relatively quiescent population of oligodendrocyte precursor cells. J Neurosci 18:601-609.

Wolswijk G, Noble M (1992) Cooperation between PDGF and FGF converts slowly dividing $\mathrm{O}-2 \mathrm{~A}$ adult progenitor cells to rapidly dividing cells with characteristics of O-2A perinatal progenitor cells. J Cell Biol 118:889-900.

Wu Q, Miller RH, Ransohoff RM, Robinson S, Bu J, Nishiyama A (2000) Elevated levels of the chemokine GRO-1 correlate with elevated oligodendrocyte progenitor proliferation in the jimpy mutant. J Neurosci 20:2609-2617.

Wyss-Coray T, Borrow P, Brooker MJ, Mucke L (1997) Astroglial overproduction of TGF-beta 1 enhances inflammatory central nervous system disease in transgenic mice. J Neuroimmunol 77:45-50.

Yanagisawa M, Nakashima K, Arakawa H, Ikenaka K, Yoshida K, Kishimoto T, Hisatsune T, Taga T (2000) Astrocyte differentiation of fetal neuroepithelial cells by interleukin-11 via activation of a common cytokine signal transducer, gp 130, and a transcription factor, STAT3. J Neurochem 74:1498-1504.

Yuen T, Zhang W, Ebersole BJ, Sealfon SC (2002a) Monitoring G-proteincoupled receptor signaling with DNA microarrays and real-time polymerase chain reaction. Methods Enzymol 345:556-569.

Yuen T, Wurmbach E, Pfeffer RL, Ebersole BJ, Sealfon SC (2002b) Accuracy and calibration of commercial oligonucleotide and custom cDNA microarrays. Nucleic Acids Res 30:e48.

Zezula J, Casaccia-Bonnefil P, Ezhevsky SA, Osterhout DJ, Levine JM, Dowdy SF, Chao MV, Koff A (2001) p21cip1 is required for the differentiation of oligodendrocytes independently of cell cycle withdrawal. EMBO Rep 2:27-34. 